\title{
Identifikasi Vegetasi dan Fungi Mikoriza Arbuskula (FMA) pada Lahan Bekas Tambang
}

\author{
Identification of Vegetation and Arbuscular Mycorrhizal Fungi (AMF) in Former Mining Sites
}

\author{
Riko Prasetyo ${ }^{* *}$, Iwan Sasli ${ }^{2}$, dan Tris Haris Ramadhan² \\ ${ }^{1}$ Program Studi Agroteknologi, Fakultas Pertanian, Universitas Tanjungpura \\ ${ }^{2}$ Jurusan Budidaya Pertanian, Fakultas Pertanian, Universitas Tanjungpura \\ Jl. Prof. Dr. H. Hadari Nawawi Pontianak 78124, Indonesia
}

Diterima 3 Februari 2019/Disetujui 31 Juli 2019

\begin{abstract}
Revegetation of former gold mining land is expected to restore soil fertility. One of the ways to use the gold-mined land as agricultural land is by utilizing the symbioses of arbuscular mycorrhizal fungi (AMF), which is expected to accelerate the revegetation process. The aim of the study was to analyze vegetation and to explore AMF in a secondary forest land (SF) and a former gold mining land (FGML) in the Mandor District. The research stages were conducting the plant identification and the exploration of AMF at the laboratory of Pests and Diseases of Faculty of Agriculture, University of Tanjungpura. The research was conducted for approximately two months, from February to April 2018. The observations include calculation of the summed dominance ratio (SDR) values, diversity index (DI), and the identification of spore. The research finding showed that based on the SDR, there were two dominant plants, i.e. Paspalum conjugatum and Melastoma candidum. The DI was categorized as 'moderate' in three locations of observation. The observation of DS in SF obtained the highest value of 750 spores $100 \mathrm{~g}$ soil. The total genus Glomus in $\mathrm{SF}$ and FGML > 10 years had a higher value than genus Acaulospora. In the three locations, genus Glomus and Acaulospora was obtanined. There was an infection at the observation of staining roots; it was characterized by the existence of arbuscular, vesicles, and external hyphae.
\end{abstract}

Keywords: mycorrhizal exploration, former gold mining land, root staining

\section{ABSTRAK}

Revegetasi lahan bekas penambangan emas diharapkan dapat mengembalikan kesuburan tanah. Pemanfaatan fungi mikoriza arbuskula (FMA) diharapkan dapat mempercepat proses revegetasi. Tujuan penelitian yaitu untuk menganalisis vegetasi dan eksplorasi FMA yang ada di lahan hutan sekunder (LHS) dan lahan bekas penambangan emas (LBPE) di Kecamatan Mandor. Tahapan penelitian yaitu melakukan identifikasi tumbuhan, serta eksplorasi FMA di Laboratorium Hama dan Penyakit Fakultas Pertanian Universitas Tanjungpura. Penelitian dilaksanakan pada bulan Februari-April 2018. Pengamatan meliputi perhitungan nilai summed dominance ratio (SDR), indeks keanekaragaman (IK), dan identifikasi mikoriza (IM). Hasil penelitian menunjukkan bahan dari perhitungan SDR didapatkan dua tumbuhan yang dominan yaitu

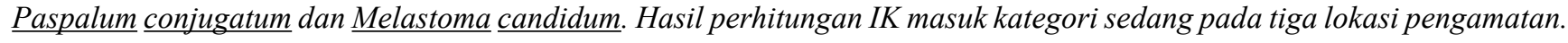
Jumlah total genus Glomus pada LHS dan (LBPE) > 10 tahun memiliki nilai yang lebih tinggi di bandingkan genus Acaulospora. Pada tiga lokasi pengamatan didapatkan genus Glomus dan Acaulospora. Pada pengamatan staining akar terjadi infeksi ditandai dengan ditemukannya vesikula, arbuskula, dan hifa eksternal.

Kata kunci: eksplorasi mikoriza, lahan pasca penambangan emas, pewarnaan akar

\section{PENDAHULUAN}

Kegiatan penambangan emas selain menimbulkan dampak positif, juga dapat menimbulkan dampak negatif

\footnotetext{
* Penulis untuk korespondensi. e-mail: rikoprasetyo326@gmail. com
}

terhadap lingkungan hidup dan lahan pertanian seperti penurunan kualitas tanah, hilangnya unsur hara dan penurunan permukaan air tanah. Vegetasi lahan bekas penambangan emas diharapkan dapat dimanfaatkan kembali untuk lahan pertanian dan dapat membentuk ekosistem yang baru yang lebih baik. Salah satu cara untuk mempercepat penanaman komoditi pertanian di lahan bekas tambang yaitu dengan memanfaatkan fungi mikoriza arbuskula 
(FMA) yang dapat bersimbiosis dengan tanaman inang yang toleran terhadap lahan-lahan yang terdegradasi karena bekas penambangan.

Perez dan Urcelay (2009) menyatakan bahwa FMA mampu meningkatkan pertumbuhan tinggi tanaman inang tertentu yang kompatibel dengan FMA. Satu jenis FMA tertentu dapat menimbulkan pengaruh yang berbeda pada tanaman inang yang berbeda. FMA merupakan pupuk hayati yang hanya cukup satu kali saja diinfeksikan kepada tanaman inangnya, karena FMA merupakan makhluk hidup yang dapat terus tumbuh dan berkembang (Setiadi dan Setiawan, 2011). Menurut Syamsiah (2014) inokulasi FMA dapat meningkatkan jumlah anakan padi IR 64 38\% dibandingkan tanpa pemberian FMA. Hasil penelitian Margarettha et al. (2017) menjelaskan bahwa pemberian FMA nyata meningkatkan hasil padi gogo. Dijelaskan juga pada penelitian Syamsiah et al. (2014) FMA mampu berinteraksi terhadap tanah dan menyuplai hara yang cukup dan meningkatkan dalam proses fotosintesis, memberikan kontribusi pada hasil tanaman padi gogo.

Effendy dan Wijayani (2011) melaporkan bahwa kecepatan masuknya hara P ke dalam hifa FMA dapat mencapai enam kali lebih cepat pada akar tanaman yang terinfeksi FMA dibandingkan dengan yang tidak terinfeksi FMA. Hal ini terjadi karena jaringan hifa eksternal FMA mampu memperluas bidang serapan. Informasi mengenai mikoriza yaitu hubungan antara fungi dan tanaman inang pada lahan bekas tambang emas di Kalimantan Barat selama ini masih jarang didapatkan. Oleh karena itu penelitian ini dilakukan untuk mengetahui kelompok FMA yang ada pada vegetasi di lokasi penelitian. Penemuan spora lokal dari Kecamatan Mandor yang menginfeksi tumbuhan dengan baik diharapkan dapat membantu pertumbuhan dan perkembangan tanaman pertanian di lahan bekas tambang. Tujuan penelitian yaitu untuk menganalisis vegetasi dan eksplorasi FMA yang ada di lahan hutan sekunder (LHS) dan lahan bekas penambangan emas (LBPE) di Kecamatan Mandor.

\section{BAHAN DAN METODE}

Penelitian dilaksanakan di Kecamatan Mandor, Kabupaten Landak, Provinsi Kalimantan Barat pada Februari-April 2018, dengan titik koordinat $0^{\circ} 15^{\prime}$ $0^{\circ} 20^{\prime}$ LU dan $109^{\circ} 18^{\prime}-109^{\circ} 23^{\prime}$ BT. Petak penelitian dan penentuan titik pengambilan contoh tanah ditentukan secara purposive sampling $20 \mathrm{~m}$ × $20 \mathrm{~m}$ pada tiga lokasi pengamatan yaitu LHS, LBPE $<10$ tahun dan LBPE $>$ 10 tahun. Penelitian dilaksanakan dalam dua tahap. Tahap pertama yaitu pengambilan data identifikasi tumbuhan yang dilaksanakan di LHS dan LBPE $<10$ tahun dan LBPE $>10$ tahun. Jenis dan jumlah tumbuhan didata dan diamati untuk mendapatkan nilai summed dominance ratio (SDR). Analisis vegetasi dimaksudkan untuk mencari nilai SDR yaitu dengan membagi tiga INP. INP = kerapatan relatif $(\mathrm{KR} \%)$ + frekuensi relatif (FR\%) dan indeks keanekaragaman (IK) dihitung dengan menggunakan Indeks Shannon-Wiener : H' $=-\sum \mathrm{Pi}$ In Pi $\mathrm{Pi}=$ ni/N (Magurran, 1988). Pengamatan eksplorasi FMA terdiri atas kepadatan spora (KS), frekuensi relative (FR), identifikasi spora, dan staining akar.

Tahap kedua yaitu eksplorasi FMA dilaksanakan dengan mengambil sampel tanah dan akar semua jenis tumbuhan. Pengamatan pada sampel tanah untuk isolasi spora dilakukan dengan metode tuang saring basah dan dilanjutkan dengan metode sentrifugasi. Spora yang lengkap struktur morfologinya diisolasi. Beberapa spora yang sudah diisolasi selanjutnya dibuat preparat untuk diidentifikasi (Brundrett et al.,1996). Pengamatan pada akar tumbuhan yaitu akar dicuci dengan aquades sampai bersih, selanjutnya akar tersebut direndam dalam larutan $\mathrm{KOH}$ $10 \%$ selama $1 \times 24$ jam setelah itu, akar dicuci dengan air mengalir 3-5 kali kemudian rendam dalam aquades selama 10-30 menit dan dicuci menggunakan air mengalir 3-5 kali. Tahap berikutnya akar direndam dalam $\mathrm{HCl} 2.5 \%$ selama 1x12 jam. Setelah akar dicuci dengan air mengalir 3-5 kali, lalu direndam dalam larutan tripan blue kemudian diganti dengan larutan destaining untuk menghilangkan kelebihan larutan tripan blue. Akar dipotong kurang lebih $1 \mathrm{~cm}$ dan kemudian diletakkan sejajar dengan rapi pada kaca preparat. Setiap 10 potong akar ditutup dengan cover glass dilakukan pengamatan pada setiap potongan akar menggunakan mikroskop dan dilihat struktur mikorizanya. Penggunaan larutan $\mathrm{KOH} 10 \%$ dimaksudkan untuk mengeluarkan cairan sitoplasma akar, sehingga akar pucat dan sebagai pengawet sedangkan larutan $\mathrm{HCl} 2.5 \%$ dimaksudkan untuk mempermudah saat pewarnaan trypan blue. Pengamatan sampel tanah dan akar di laksanakan di Laboratorium Hama dan Penyakit Universitas Tanjungpura.

\section{HASIL DAN PEMBAHASAN}

\section{Summed Dominance Ratio (SDR)}

Hasil pengamatan menunjukkan tingkat habitus yang mendominansi adalah Paspalum conjugatum dengan nilai SDR sebesar 0.1115, sedangkan Melastoma candidum memiliki nilai SDR tertinggi pada LBPE $<10$ tahun sebesar 0.2326 dan 0.1728 pada LBPE $>10$ tahun. Jenisjenis yang mempunyai peranan besar (dominan) dalam komunitas akan mempunyai SDR tinggi (Martono, 2012). Hasil perhitungan SDR didapatkan Paspalum conjugatum merupakan tumbuhan yang paling dominan hal ini di sebabkan karena tumbuhan yang berasal dari Amerika ini perberkembang biakannya menggunakan biji dan juga akar rimpang, namun penyebaran melalui biji lebih berpotensi karena Paspalum conjugatum memiliki biji yang cukup banyak. Paspalum conjugatum dapat berkembang dengan baik di kondisi yang memiliki intensitas cahaya matahari dan kelembaban udara yang cukup yang memungkinkan jenis ini untuk berkecambah dengan baik (Binibis, 2014). Hasil perhitungan SDR di LHS, LBPE $<10$ tahun dan LBPE $>10$ tahun dapat dilihat pada Tabel 1 .

Hasil penelitian pada lokasi LBPE $<10$ tahun dan LBPE > 10 tahun menunjukkan Melastoma candidum mampu hidup pada tanah masam dan di daerah yang miskin hara pada lahan bekas tambang dengan nilai SDR 0.6977 dan 
Prasetyo et al. / J. Agron. Indonesia 47(2):217-223

Tabel 1. Hasil perhitungan summed dominance ratio (SDR) di LHS, LBPE $<10$ tahun dan LBPE $>10$ tahun

\begin{tabular}{|c|c|c|c|}
\hline \multirow{2}{*}{ Nama tumbuhan } & \multicolumn{3}{|c|}{ Summed dominance ratio (SDR) } \\
\hline & LHS & LBPE $<10$ tahun & LBPE $>10$ tahun \\
\hline Accaciae mangium Wild. & & 0.0394 & 0.0186 \\
\hline Ananas comosus (L.) Merr. & & 0.0049 & \\
\hline Axonopus compressus (Swartz.) Beauv. & 0.0799 & & 0.0401 \\
\hline Bellucia axinanthera Triana. & & & 0.0125 \\
\hline Bulbostylis capilaris (L.) Kunth. & & 0.0701 & \\
\hline Carallia brachiata (Lour.) Merr. & 0.0381 & & \\
\hline Cyperus rotundus (L.) & 0.1020 & & \\
\hline Dicranopteris linearis (Burm. f.) Underw. & & 0.0394 & 0.0587 \\
\hline Dillenia indica (L.) & 0.0095 & 0.0174 & \\
\hline Eleusine indica (L.) Gaertn. & 0.0668 & & \\
\hline Gonystylus bancanus Kurz. & 0.0225 & & \\
\hline Hevea brasiliensis Muell. Arg. & & & 0.0433 \\
\hline Hibiscus macrophyllus Roxb. & 0.0192 & & \\
\hline Imperata cylindrica (L.) Raeusch. & & 0.0481 & \\
\hline Lepironia articulate (Retz.) Domin. & & & 0.0494 \\
\hline Lycopodiella cernua (L.) Pic. Serm. & & 0.1928 & \\
\hline Melastoma candidum (L.) & 0.0160 & 0.2326 & 0.1728 \\
\hline Pandanus tectorius Parkinson. & 0.0606 & & \\
\hline Paspalum conjugatum Berg. & 0.1115 & & \\
\hline Pennisetum purpureum Schaum. & & & 0.0930 \\
\hline Pterospermum javanicum Jungh. & & & 0.0215 \\
\hline Rhodomyrtus tomentosa Wight. & 0.0127 & & \\
\hline Scleria sumatrensis Retz. & & 0.0220 & \\
\hline Stenochlaena palustris Bedd. & 0.0701 & & 0.1295 \\
\hline Tristaniopsis obovata Benn. & 0.0291 & & \\
\hline Vaccinium varingiaefolium (B1.) Miq. & 0.0287 & & \\
\hline
\end{tabular}

Keterangan: Lahan hutan sekunder (LHS), lahan bekas penambangan emas (LBPE) < 10 tahun, dan lahan bekas penambangan emas $(\mathrm{LBPE})>10$ tahun

0.5183 hal ini sesuai dengan pernyataan Netty et al. (2012) Melastoma malabatricum yang juga masuk kedalam famili Melastomaceae dilaporkan dapat tubuh pada lahan pasca tambang PT. Inco Tbk. Site Sorowako. Menurut Tanasale (2012) nilai SDR tertinggi pada suku Melastomaceae terdapat pada jenis Melastoma affine $17.86 \%$ dan dinyatakan sebagai gulma dominan. Gulma Melastoma affine dapat tumbuh dengan kondisi intensitas cahaya yang tinggi, tajuk yang agak ternaungi dengan kondisi memungkinkan gulma ini mampu tumbuh dan berkembang dengan cepat dari pada gulma lainnya.

\section{Indeks Keanekaragaman (IK)}

Pengamatan yang dilakukan pada lokasi LHS, LBPE $<10$ tahun dan LBPE $>10$ tahun di Kecamatan Mandor menghasilkan angka IK tertinggi yaitu pada LHS sebesar $1<1.2382<3$. Hal ini menunjukkan bahwa jumlah total individu seluruh jenis yang ada termasuk ke dalam kategori keragaman spesies sedang. Begitu juga pada LBPE $>10$ tahun memiliki nilai IK sedang yaitu $1<1.1789<3$. Nilai IK menunjukkan bahwa jumlah jenis diantara jumlah total individu seluruh jenis yang ada termasuk dalam kategori sedang. Kategori tersebut mengartikan bahwa komunitas sedang menuju pada kondisi yang stabil. Zainullah et al. (2017), menyatakan bahwa nilai $\mathrm{H}^{\prime} 1 \leq \mathrm{H}^{\prime} \leq 3$ menunjukkan bahwa keanekaragaman jenis pada suatu kawasan adalah sedang.

Nilai IK pada petak lokasi penelitian LBPE $<10$ tahun adalah $0.8069<1$. Hal ini menunjukkan bahwa nilai keanekaragaman jenis LBPE $<10$ tahun Kecamatan Mandor termasuk dalam kategori rendah sesuai pernyataan Indriani 
(2009). Jika kriteria nilai IK Shannon-Weiner adalah H' < 1 = keanekaragaman rendah, H' 1-3 = keanekaragaman sedang, dan H'> 3 = keanekaragaman tinggi. Ketersediaan nutrisi dan pemanfaatan nutrisi yang berbeda menyebabkan nilai IK bervariasi.

\section{Identifikasi Mikoriza (IM)}

Hasil pengamatan terhadap kerapatan spora pada rhizosfer tanah dengan total 14 spesies di LHS sebesar 750 spora/100 g tanah. Tumbuhan yang terbanyak ditemukan spora di LHS yaitu Stenochlaena palustris yang memiliki nilai kerapatan 67 spora/100 g tanah dan Cyperus rotundus yang memiliki nilai kerapatan 60 spora/100 g tanah. Pada LBPE $<10$ tahun tumbuhan yang diperoleh sebanyak 12 spesies dengan nilai total kerapatan 374 spora/100 g tanah. Kerapatan spora (KS) di LHS, LBPE $<10$ tahun dan LBPE $>10$ tahun dapat dilihat pada Gambar 1 .

Hevea brasiliensis merupakan tumbuhan yang terbanyak ditemukannya spora di LBPE $<10$ tahun dengan nilai kerapatan 50 spora/100 g tanah. Berikutnya adalah Accaciae mangium memiliki nilai kerapatan 45 spora/100 g tanah dan pada LBPE $>10$ tahun tumbuhan yang diperoleh sebanyak 9 spesies dengan nilai total kerapatan 458 spora/ 100 $\mathrm{g}$ tanah. Tumbuhan Lycopodiella cernua merupakan spesies yang terbanyak ditemukan spora yaitu 52 spora/100 g tanah dan Bulbostylis capilaris yang memiliki nilai kerapatan 50 spora/100 g tanah. Hasil analisis kerapatan spora pada LHS, LBPE $<10$ tahun dan LBPE $>10$ tahun dapat dilihat pada Tabel 2.

Hasil pewarnaan akar pada tumbuhan Stenochlaena palustris didapatkan morfologi FMA yaitu vesikula, arbuskula, dan hifa eksternal. Hal ini sesuai dengan pernyataan (Setiadi dan Setiawan, 2011) bahwa dengan adanya salah satu struktur dari FMA yaitu vesikula, arbuskula dan hifa eksternal, maka dapat dikatakan terjadi infeksi oleh FMA. Struktur hifa di dalam akar tanaman dan tanah mampu meningkatkan luas areal untuk pertukaran hara dan air antara tanaman dan inang, sehingga mempunyai potensi

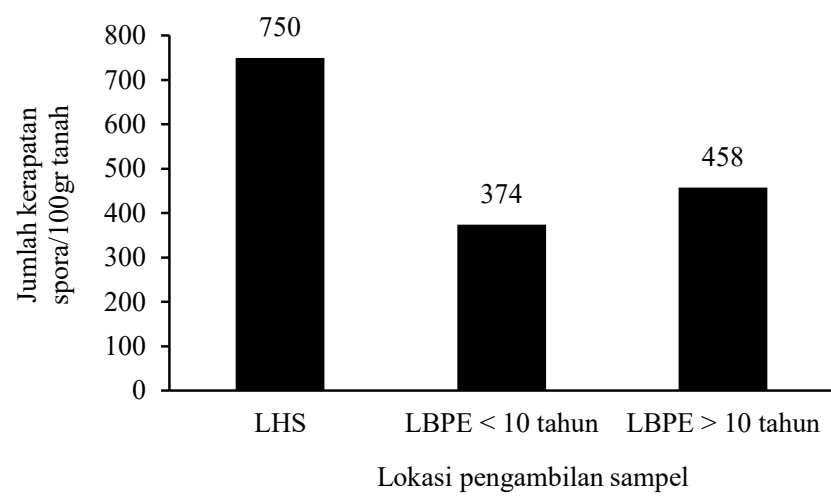

Gambar 1. Kerapatan spora (KS) di Lahan hutan sekunder (LHS), lahan bekas penambangan emas (LBPE) $<10$ tahun dan lahan bekas penambangan emas (LBPE) $>10$ tahun yang besar untuk meningkatkan serapan dan translokasi hara terutama unsur P ke tanaman (Utama dan Yahya, 2003). Hasil pewarnaan pada akar tumbuhan Stenochlaena palustris dapat dilihat pada Gambar 2 .

Hasil identifikasi morfologi (bentuk dan warna) FMA menunjukkan dua genus yang ditemukan dari LHS, LBPE $<10$ tahun dan LBPE $>10$ tahun yaitu genus Glomus dan Acaulospora. Genus Glomus dicirikan dengan spora berbentuk bulat, warna coklat kemerahan dan permukaan spora halus sesuai dengan pernyataan INVAM (2014) genus Glomus bentuk bulat, dinding spora terdiri atas lebih dari satu lapis. Warna spora genus Glomus bervariasi mulai dari kuning, kuning kecoklatan, coklat kekuningan, coklat muda, hingga coklat tua kehitaman dan genus Glomus dapat berkembang dengan baik pada $\mathrm{pH} 5.5$ sampai 6.5, sedangkan genus Acaulospora dicirikan dengan memiliki bentuk globus, sub globus, irregular hingga elips. Dinding spora terdiri dari 2 lapisan di mana dinding spora terdalam dilengkapi dengan germination orb. Warna spora bervariasi mulai dari kuning, oranye, kecoklatan, merah tua hingga merah kecoklatan INVAM (2017). Hasil pengamatan genus Glomus di lahan bekas tambang emas dapat dilihat pada Gambar 3.

Hormon yang dihasilkan oleh mikoriza didalam pupuk hayati akan diserap oleh tanaman sehingga tanaman akan tumbuh lebih cepat atau lebih besar serta hasil tanaman juga akan maksimal. Hasil penelitian Irwan dan Wahyudin (2017) menunjukkan perlakuan 5 g polibag-1 MVA dan perlakuan $20 \mathrm{cc} / \mathrm{L}$ pupuk pelengkap cair, memberikan pengaruh yang lebih baik terhadap tinggi tanaman, indeks luas daun, jumlah cabang produktif dan jumlah buku subur, jumlah polong isi dan jumlah polong hampa per tanaman, bobot 100 butir, bobot biji per tanaman dan indeks panen tanaman kedelai. Hasil penelitian Damanik dan Suryanto (2018) menunjukkan terdapat pengaruh nyata penggunaan mikoriza dan PGPR terhadap parameter panjang tanaman. Media tanam yang diberi bahan organik memiliki panjang tanaman yang sama dengan media tanam yang diberi mikoriza, PGPR, bahan organik + mikoriza, bahan organik + PGPR. Perlakuanyang menghasilkan panjang tanaman paling tinggi yaitumedia tanah + bahan organik + mikoriza. Hal ini dikarenakan mikoriza ialah salah satu pupuk hayati yang mampu meningkatkan serapan unsur hara $\mathrm{P}$ dalam tanah. Hasil pengamatan genus Glomus di lahan bekas tambang emas dapat dilihat pada Gambar 3.

Suharno dan Sancayaningsih (2013) mengungkapkan bahwa beberapa jenis FMA yang sering dimanfaatkan dalam proses revegetasi lahan tambang diantaranya adalah Glomus mosseae, Glomus intraradices dan Glomus caledonium. Jenis FMA ini mampu berkontribusi besar terhadap ketahanan dan peningkatan pertumbuhan tanaman dalam usaha rehabilitasi lahan tambang. Hal ini sejalan dengan penelitian Setiadi (2011) yang menunjukkan bahwa jenis mikoriza Gigaspora margarita, Acaulospora sp. dan Glomus sp. mampu bertahan pada kondisi lahan pasca pertambangan nikel. 
Tabel 2. Hasil analisis kerapatan spora pada LHS, LBPE $<10$ tahun dan LBPE $>10$ tahun

\begin{tabular}{|c|c|c|}
\hline Lokasi pengambilan sampel & Jenis tumbuhan & Kerapatan spora/100 g tanah \\
\hline \multirow[t]{14}{*}{$\overline{\text { LHS }}$} & Stenochlaena palustris Bedd. & 67 \\
\hline & Cyperus rotundus (L.) & 60 \\
\hline & Paspalum conjugatum Berg. & 60 \\
\hline & Tristaniopsis obovata Benn. & 56 \\
\hline & Dillenia indica (L.) & 55 \\
\hline & Gonystylus bancanus Kurz. & 55 \\
\hline & Rhodomyrtus tomentosa Wight. & 54 \\
\hline & Melastoma candidum (L.) & 53 \\
\hline & Hibiscus macrophyllus Roxb. & 50 \\
\hline & Vaccinium varingiaefolium (BI.) Miq. & 50 \\
\hline & Eleusine indica (L.) Gaertn & 50 \\
\hline & Pandanus tectorius Parkinson. & 52 \\
\hline & Carallia brachiata (Lour.) Merr. & 45 \\
\hline & Axonopus compressus (Swartz) Beauv. & 43 \\
\hline \multirow[t]{12}{*}{ LBPE $<10$ Tahun } & Hevea brasiliensis Muell. Arg. & 50 \\
\hline & Accaciae mangium Wild. & 45 \\
\hline & Stenochlaena palustris Bedd. & 45 \\
\hline & Lycopodiella cernua (L.) Pic. Serm. & 41 \\
\hline & Cyperus rotundus (L.) & 38 \\
\hline & Belluchia axinanthera Triana. & 37 \\
\hline & Pterospermum javanicum Jungh. & 37 \\
\hline & Pennisetum purpureum Schaum. & 36 \\
\hline & Axonopus compressus (Swartz) Beauv. & 36 \\
\hline & Lepironia articulate (Retz.) Domin. & 35 \\
\hline & Dicranopteris linearis (Burm. f.) Underw & 31 \\
\hline & Melastoma candidum (L.) & 27 \\
\hline \multirow[t]{9}{*}{ LBPE $>10$ Tahun } & Lycopodiella cernua (L.) Pic. Serm. & 52 \\
\hline & Bulbostylis capilaris (L.) Kunth. & 50 \\
\hline & Ananas comosus (L.) Merr. & 48 \\
\hline & Melastoma candidum (L.) & 48 \\
\hline & Imperata cylindrica (L.) Raeusch. & 47 \\
\hline & Dicranopteris linearis (Burm. f.) Underw & 40 \\
\hline & Scleria sumatrensis Retz. & 32 \\
\hline & Accaciae mangium Wild. & 30 \\
\hline & Dillenia indica (L.) & 27 \\
\hline
\end{tabular}

Keterangan: Lahan hutan sekunder (LHS), lahan bekas penambangan emas (LBPE) $<10$ tahun, dan lahan bekas penambangan emas $(\mathrm{LBPE})>10$ tahun 


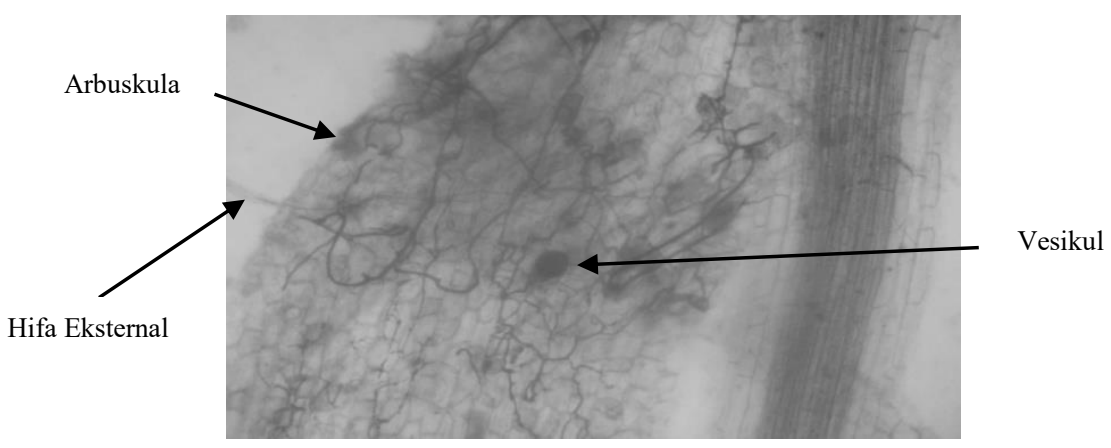

Gambar 2. Hasil pengamatan pewarnaan pada akar tanaman Stenochlaena palustris

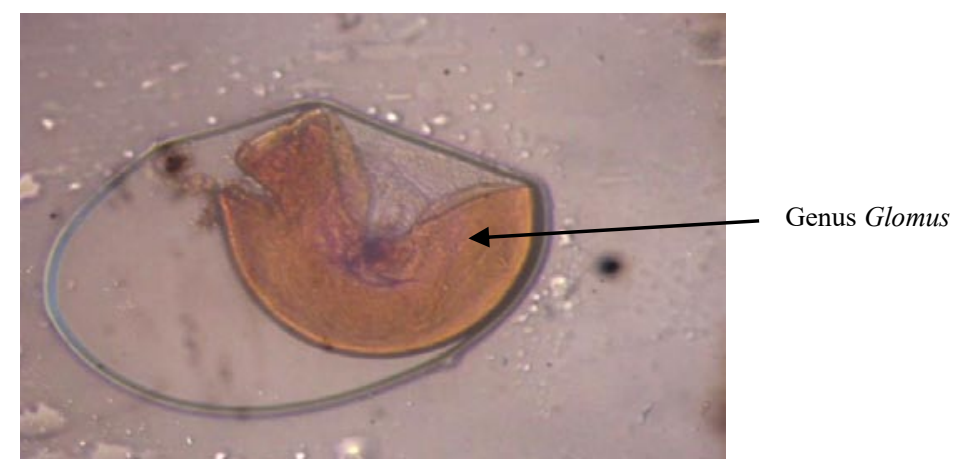

Gambar 3. Hasil pengamatan genus Glomus di lahan bekas tambang emas

\section{KESIMPULAN}

Nilai summed dominance ratio (SDR) yang tertinggi pada LHS adalah Paspalum conjugatum sedangkan pada $\mathrm{LBPE}<10$ tahun dan LBPE $>10$ tahun nilai SDR tertinggi adalah Melastoma candidum sehingga tumbuhan tersebut memiliki tingkat dominansi yang tinggi dan paling baik dalam beradaptasi dengan tempat tumbuhnya. Hasil eksplorasi FMA pada semua jenis tumbuhan menunjukkan bahwa genus yang paling dominan adalah Glomus dan Acaulospora. Pada perakaran Stenochlaena palustris terjadi infeksi oleh FMA yaitu dengan ditemukannya struktur vesikula, arbuskula dan hifa eksternal.

\section{DAFTAR PUSTAKA}

Binibis, L. 2014. Inventarisasi tumbuhan bawah di kawasan penambangan emas Desa Juria Kecamatan Bilato Kabupaten Gorontalo. Tesis. Universitas Gorontalo, Sulawesi.

Brundrett, M., N.L. Bougher, B. Dell, T.S. Groove, N. Malajczuk. 1996. Working with Mycorrhizas in Forestry and Agriculture. Australian Centre for International Agricultural Research, Canberra, AU.

Damanik, S.A., A. Suryanto. 2018. Efektivitas penggunaanmikoriza dan PGPR terhadap tanaman bawang merah (Allium ascalonium L.) pada pipa PVC sistem vertikultur. J. Produksi tanaman. 6:635641.
Effendy, M., B.W. Wijayani. 2011. Estimation of available phosphorus in soil using the population of arbuskular mycorrhizal fungi spores. J. Trop Soils. 16:225-232.

Indriani, D.P., M. Hanifah, Zakaria. 2009. Keanekaragaman spesies tumbuhan pada kawasan mangrove nipah (Nypa fruticans Wurmb) di Kec. Pulau Rimau Kab. Banyuasin Sumatera Selatan. J. Penelitian Sains. 12:1-4.

INVAM. 2017. International culture collection of(Vesicular) arbuscular mycorrhizal fungi. Diakses melalui http:// invam.caf.wvu. edu/fungi/Taxonomy/classification .html. [3 Oktober 2018].

Irwan, A.W., A.Wahyudin. 2017. Pengaruh inokulasi Mikoriza Vesikular Arbuskula (MVA) dan pupuk pelengkap cair terhadap pertumbuhan, komponen hasil dan hasil tanaman kedelai pada tanah Inceptisols Jatinangor. J. Kultivasi. 16:326-332.

Margarettha, M. Syarif, H. Nasution. 2017. Efektifitas fungi mikoriza arbuskular indigen untuk padi gogo dilahan kering Marginal. J. Ilmiah Ilmu Terapan Universitas Jambi. 1:185-191.

Martono, D.S. 2012. Analisis vegetasi dan asosiasi antara jenis-jenis pohon utama penyusun hutan tropis dataran rendah di Taman Nasional Gunung Rinjani Nusa Tenggara Barat. J. Agri-tek. 13:18-27. 
Megurran, A.E. 1988. Ecological Diversity and Its Measurement. Pricenton University Press, New Jersey, USA.

Netty, S., T. Wardiati, E. Handayanto, M.D. Maghfoer. 2012. Nickel accumulating plants in the post-mining land of Sorowako. South Sulawesi. Indonesia. J. Trop. Agric. 50:35-48.

Nurhayati, N. 2012. Pengaruh berbagai jenis tanaman inang dan beberapa jenis sumber inokulum terhadap infektivitas dan efektivitas mikoriza. J. Agrista. 16:80-86.

Perez, M., C. Urcelay. 2009. Differential growth response to arbuscular mycorrhizal fungi and plant density in two wild plants belonging to contrasting functional types. J. Mycorrhiza. 19:517-523.

Prasad, R., D. Bhola, K. Akdi, C. Cruz, Sairam KVSS, N. Tuteja, A. Varma. 2017. Introduction to mycorrhiza: historical development. p. 1-7. In A. Varma, R. Prasad, N. Tuteja (Eds.). Mycorrhiza - function, diversity, state of the art. Springer International Publising.

Setiadi, Y., A. Setiawan. 2011. Studi status fungi mikoriza arbuskula di areal rehabilitas pasca penambangan nikel (Studi Kasus PT INCO Tbk. Orowako. Sulawesi Selatan). J. Silvikultur Tropika 3:88-95.
Suharno, R.P. Sancayaningsih. 2013. Fungi mikoriza arbuskula: potensi teknologi mikorizoremediasi logam berat dalam rehabilitasi lahan tambang. Biokteknologi 10:31-42.

Syamsiah, J., B.H. Sunarminto, E. Hanudin, J. Widada. 2014. Pengaruh inokulasi jamur mikoriza arbuskular terhadap glomalin, pertumbuhan dan hasil padi. J. Ilmu Tanah dan Agroklimatologi. 11:39:46.

Tanasale, V.L. 2012. Studi komunitas gulma di pertanaman gandaria (Bouea macrophylla Griff.) pada tanaman belum menghasilkan dan menghasilkan di Desa Urimessing Kecamatan Nusaniwe Pulau Ambon. J. Budidaya Pertanian 8:7-12.

Utama, M.Z.H., S. Yahya. 2003. Peranan mikoriza VA, rhizobium dan asam humat pada pertumbuhan dan kadar hara beberapa spesies legum penutup tanah. Bul. Agron. 31:94-99.

Wanda,A.R., Yuliani, G. Trimulyono.2015.Keanekaragaman cendawan mikoriza vesikula arbuskula (MVA) di hutan pantai Vepa Sampang Madura berdasarkan gradient salinitas. J. Lentera Bio. 4:180-186.

Zainullah, Burhanudin, Fahrizal. 2017. Keanekaragaman jenis vegetasi penyusun tembawang di Desa Ngarak Kecamatan Mandor Kabupaten Landak. J. Hutan lestari 5:1008-1015. 